Abstracted/indexed in Academic Search Complete, Asia Journals Online, Bangladesh Journals Online, Biological Abstracts, BIOSIS Previews, CAB Abstracts, Current Abstracts, Directory of Open Access Journals, EMBASE/Excerpta Medica, Google Scholar, HINARI (WHO), International Pharmaceutical Abstracts, Open J-gate, Science Citation Index Expanded, SCOPUS and Social Sciences Citation Index;

\title{
Study of adverse drug reactions in out-patient departments of a teaching hospital
}

\author{
Zinnat Ara Begum, Sayeeda Sultana², Badar Uddin Umar3, A. H. Ferdous4, Md. Kamal \\ Uddin5 and S. M. Hasibul Islam6
}

${ }^{1}$ Centre for Medical Education, Mohakhali, Dhaka, Bangladesh; ${ }^{2}$ Department of Pharmacology, NICVD, Sher-eBangla Nagar, Dhaka, Bangladesh; ${ }^{3}$ Department of Pharmacology, Faridpur Medical College, Faridpur, Bangladesh; ${ }^{4}$ Department of Pharmacology, Dinajpur Medical College, Dinajpur; ${ }^{5}$ Department of Pharmacology, Khulna Medical College, Khulna; ${ }^{6}$ Department of Neurosurgery, Dhaka Medical College, Dhaka 1000, Bangladesh.

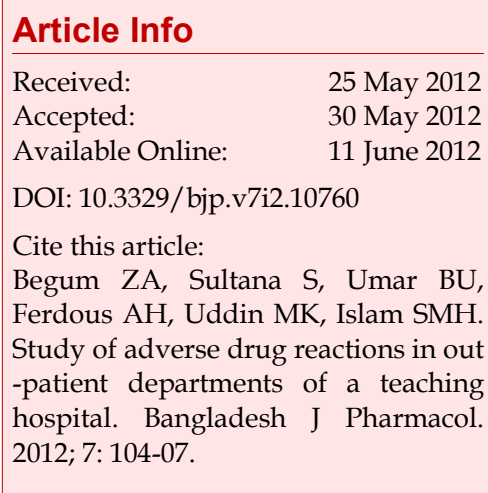

\section{Abstract}

The study conducted in the Medicine and Skin outpatient Departments of Dhaka Medical College, Dhaka revealed 19 cases (7 males, 12 females) of adverse drug reactions (ADR) out of 160 patients. 31.6\% ADRs were of mild type, $42.1 \%$ were of moderate and $26.3 \%$ were of severe in nature. Gastrointestinal complications were the most frequent adverse effect (56\%). Antimicrobial drugs were the most common cause of ADR $(42.9 \%)$ followed by NSAIDs $(33.3 \%)$. This study is a preliminary study for getting information on the pattern of ADRs in Bangladesh needing further studies.

\section{Introduction}

Adverse drug reactions (ADR) are mild and many are severe, that even cost life (Pirmohamed and Park, 2003). In the US 106,000 hospital patients died from ADRs in 1994, which was fourth to sixth leading cause of death after heart disease, cancer and stroke (Lazarou et al., 1998). It has been estimated that $3-5 \%$ of all hospitalizations can be attributed to ADRs in 3,00,000 hospitalizations annually in the US. Once hospitalized, patients have about $30 \%$ chance of an untoward event related to drug therapy and the risk attributable to each course of drug therapy is about $5 \%$. The chance of a life threatening drug reaction is about 3\% per patient in the hospital and about $0.4 \%$ per each course of therapy (Nies and Spielberg, 1996).

ADRs cause considerable economic burden on society (Lazarou et al., 1998; Singer and Khong, 2002; Reidl and Casillas, 2003; Ramesh et al., 2003; Moore et al., 1998; Pirmohamed et al., 2004).
In Bangladesh Islam and Rahman (2005) reported a case of fatal toxic epidermal necrosis due to levofloxacin and Nahar and her co-investigators (2006) studied on the adverse effects of two anti-tuberculosis drug regimen and found gastrointestinal disturbances, arthralgia, hepatic dysfunction and renal impairment before two and eight weeks after initiation of treatment. In another small study conducted in Khulna Medical College ADRs caused $25 \%$ fatality.

Drugs like carbamazepine and co-trimoxazole were the most vulnerable drugs (Chowdhury et al., 2008). A number of factors are involved in the causation of ADRs. These are- i) Availability of a large number of formulations to be prescribed, ii) physicians unawareness about all aspects of new drugs, iii) pressure by the sales-promoters of the pharmaceuticals to create a market, iv) canvassing by the detail men and even colleagues, and v) persuasion of the patients themselves to prescribe new drugs (Bhargava, 1972). Pharmacist along with other care professionals should actively 
Table I

Drug class implicated in ADR $(n=21)$

\begin{tabular}{|c|c|c|}
\hline Drug & Number of ADR & $\%$ \\
\hline Antibiotics & 9 & 42.9 \\
\hline NSAIDs & 7 & 33.3 \\
\hline Steroid & 1 & 4.8 \\
\hline Others & 4 & 19.1 \\
\hline
\end{tabular}

Table II

\begin{tabular}{|lcc|}
\hline \multicolumn{3}{|c|}{ System associated with ADR (n=25) } \\
\hline System & Number of ADR & $\%$ \\
\hline GIT & 14 & 56 \\
Skin \& Appendages & 8 & 32 \\
Musculoskeletal & 1 & 4 \\
Others & 2 & 8 \\
\hline
\end{tabular}

Table III

\begin{tabular}{|lcc|}
\hline \multicolumn{3}{|c|}{ Antibiotics associated with ADRs (n = 9) } \\
\hline Name & Number & $\%$ \\
\hline Fluroquinolones & 4 & 44.4 \\
$\beta$-Lactams & 2 & 22.2 \\
Macrolides & 2 & 22.2 \\
Co-trimoxazole & 1 & 11.1 \\
\hline
\end{tabular}

involve in ADR monitoring and reporting (Reidl and Casillas, 2003).

Data regarding adverse drug reaction of Bangladesh are not properly recorded (BDNF, 2001). Considering this the study is designed to find out the extent of problem of ADR and provide a baseline data which may help to improve the activity of ADR monitoring cell promotion of RUD thereby reduce the ADR.

\section{Materials and Methods}

A prospective, cross-sectional and descriptive study from July 2007 to June 2008 was carried out by the Department of Pharmacology and Therapeutics in Medicine and Skin outpatient Department of Dhaka Medical College Hospital. A total of 160 patients were selected randomly by non-probability or purposive sampling. Among them the patients suspected of ADRs attending the departments were interviewed. Data were collected by a structured questionnaire, designed for collecting information like-name, age, sex, weight, occupation, socio-economic status etc. WHO definition and classifications of ADR were followed. The initial history included a recording of all prescriptions and non-prescription drugs taken within the last one month, including dates of administration and dosage and also the history of previous drug exposure and reactions, family history of drug reactions, features and severity of ADR etc. Data were analyzed by using percentage.

\section{Results}

A total of 19 (7 males, 12 females) were diagnosed as case of ADR. Number of patients in 0-18 years age group were 3, 19-60 years age group were 14 and above 60 years were 2 . In 19 cases, 21 medicines were suspected to cause 25 ADRs. Six patients suffered from multiple ADRs. Drug class implicated in ADR cases and the system affected are shown in Table I and II. Among the ADRs 6 (31.6\%) were of mild type, 8 (42.1\%) were of moderate and $5(26.3 \%)$ were of severe in nature.

All the cases of ADR were evaluated for causality assessment by Naranjo's scale and all the 25 ADRs fell in probable category. Gastrointestinal complications were the most frequent adverse effect. 14 (56\%) out of 25 ADR showed various forms of GIT symptoms. The next commonest ADR involved the skin and appendages which were $8(32 \%)$ in number. Antibiotics were the most common cause of ADR. Out of 25 ADR 9 $(42.9 \%)$ were due to antibiotics and $7(33.3 \%)$ were due to NSAID. Among the antibiotics, fluroquinolones showed highest number (Table III). No new drugs were taken by any patient during the study period. Also no unknown side effects for an established drug were reported by the patient during this period.

\section{Discussion}

From November 2007 to April 2008 a total of 109,528 patients attended the Medicine Outpatient Department $(79,397)$ and Skin Outpatient Department $(30,131)$ of Dhaka Medical College. Out of which 160 patients were randomly surveyed. 19 patients were found to have ADR with certain drugs. In one patient ADR occurred after taking homeopathic medicine. In 19 ADR cases a total of 66 drugs were taken by the patients. Other studies also showed incidence and prevalence of ADRs in similar percentages (Lazarou et al., 1998; Pirmohamed et al., 2004; Gor and Desai, 2008; Palain et al., 2006; Giovanni et al., 2006; Beijer and de Baley, 2002). The Canadian Adverse Reaction Monitoring Program (CADRMP) received 5688 reports of suspected ADRs in 1999. Out of which 2999 were labeled as serious. In 2000 this figure was 7361 and 3343 respectively (Canadian ADR Newsletter, 2000; Canadian ADR Newsletter, 2001). In this study most of the adverse effects were due to antibiotics, this was consistent with other studies (Moore et al., 1998; Nahar 
et al., 2006; Chowdhury et al., 2008; Rao et al., 2006; Suh et al., 2000). Antibiotics were followed by NSAIDs, steroids and other drug classes in causing ADRs in this study. This observation is also consistent with studies conducted by other investigators (Moore et al., 1998; Pirmohamed et al., 2004; Giovanni et al., 2006; Rao et al., 2006). Gastrointestinal system was the commonest system affected by ADRs; this finding is consistent with the report of other studies (Ramesh et al., 2003; Pirmohamed et al., 2004; Canadian ADR Newsletter, 2000; Rao et al., 2006; Pouyanne et al., 2000; Brvar et al., 2009). In this study all the ADRs belonged to probable category according to Naranjo's scale of causality. But this finding did not match with Lei et al. (2007) who revealed in their study that according to Naranjo's algorithm 16.4, 83.1 and $0.5 \%$ ADRs were categorized as 'probable', 'possible' and 'unlikely' category respectively. In another study McDonnell and Jacobs (2002) showed that most ADR admissions (97.4\%) were of 'probable' or 'highly probable' category. Rao et al. (2006) found most of the ADRs to be of 'possible' category (52.3\%) followed by 'probable' (46.2\%) and 'unlikely' (1.5\%). A study conducted in different hospitals in Kathmandu, Nepal showed that 35\% of ADRs were 'probable', 32\% 'possible' and 19\% were 'definite' category according to Naranjo's scale. This difference might be due to inclusion of only the reported cases of ADRs in the Medicine and Skin Outpatient Departments of DMCH. As well the small size of the sample has contributed to such a result.

Between 1998 and 2005 there was an increase in the numbers of ADRs by 455 in England. And the data suggested that there were limitations in studies resulting in under-recording of ADR cases (Patel et al., 2007). At present pharmacovigilance is predominantly based on spontaneous reports. About $50 \%$ of the ADRs are potentially avoidable. So, there is room for improvement (National Medicines Information Centre, 2002). Research is essential to detect, understand, predict and ultimately reduce the burden of ADRs. There should be increase research funding by the governments to improve this situation (Pirmohamed and Park, 2003). It has been suggested that improved and more detailed reporting, educational interventions are necessary to have accurate monitoring of ADRs (Patel et al., 2007). Improvement of systems by which drugs are ordered and administered could prevent many ADRs and will reduce costs (Bates et al., 1995). Spontaneous reporting of ADRs remains the cornerstone of pharmacovigilance and is important in maintaining patient safety (Green et al., 2001). Education and training of the hospital pharmacists will be supportive in maintaining and increasing ADR reports (Green et al., 2001). In Bangladesh importance of ADRs is still underestimated with inadequate reporting, inappropriate data collection, storage and analysis. Though they are common, life threatening and unnecessarily expensive, they are avoidable. What needed is consciousness build up among all the persons involved in health service-doctors, nurses and pharmacists. ADRs are negative consequences of drug therapy which has major clinical public health and economic burden but it is not well recorded in Bangladesh. This study is a preliminary study for getting information on the pattern of ADRs in a limited way in two Outdoor Patient Department of only one teaching hospital. This needs further extensive study. It indicates a need for a strong national ADRs program that detects and reports adverse drug reaction in Bangladesh. ADRs program should also include awareness and motivation of the healthcare professionals about reporting of ADRs which will have a positive influence.

\section{Acknowledgement}

The authors acknowledge all the doctors and staff of Medical Outpatient Department and Skin Outpatient Department for their kind help and support in collecting data for the study. The study is funded by the research grant of fiscal year 2007 2008 of Dhaka Medical College.

\section{References}

Bates DW, Cullen DJ, Laird N, Petersen LA, Small SD, Servi D, et al. Incidence of adverse drug events and potential adverse drug events implication for prevention. JAMA. 1995; 274: 2934.

BDNF. Adverse Drug Reactions Monitoring (ADRM). 3rd ed. Nov. Directorate of Drug Administration, BMA \& Bangladesh Pharmaceutical Society, 2001, pp 600-08.

Beijer HMJ, de Baley CJ. Hospitalizations caused by adverse drug reactions (ADR): A meta-analysis of observational studies. J Pharm World Sci. 2002; 24: 46-54.

Bhargava KP. Basic mechanism of adverse drug reactions. Ind J Pharmac. 1972; 4: 35-50.

Brvar M, Fokter N, Bunc M, Mozina M. The frequency of adverse drug reaction related admissions according to method of detection, admission urgency and medical department specialty. BMC Clin Pharmacol. 2009; 9: 1-8.

Canadian ADR Newsletter Apr. 2000; 10 (2): 1. accessed on 06.05.2010 at www.hc-sc.gc.ca/hpb-dgps/therapeut/ htmleng/publicat.html.

Chowdhury FR, Mohammed FR, Alam MZ, Nur Z, Hoque MA, Uddin MM, Bakar MA. Etiology and outcome of patients admitted in a tertiary level hospital with adverse drug reaction (ADR). J Dhaka Med Coll. 2008; 17:17-21.

Giovanni P, Francesco S, Paola C, Ilaria M, Caputi AP. Adverse drug reactions induced by NSAIDs and antimicrobials: Analysis of spontaneous reports from the Sicilian regional database. Drug Safety. 2006; 29: 449-59.

Gor AP, Desai SV. Adverse drug reaction (ADR) in the patient of medicine department of a rural tertiary care teaching 
hospital and influence of pharmacovigilance in reporting ADR. Indian J Pharmacol. 2008; 40: 37-40.

Green CF, Mottram DR, Rowe PH, Pirmohamed M. Attitudes and knowledge of hospital pharmacists to adverse drug reaction reporting. Br J Clin Pharmacol. 2001; 51: 81-86.

Islam AFMS, Rahman MS. Levofloxacin-induced fatal toxic epidermal necrolysis. Ann Pharmacother. 2005; 39: 1136-37.

Laurence DR, Bennett PN. Unwanted effects and adverse drug reaction. In: Clinical pharmacology. 9th ed. UK, Churchill Livingstone, 2003, p 135.

Lazarou J, Pomeranz BH, Corey PN. Incidence of adverse drug reactions in hospitalized patients: A meta-analysis of prospective studies. JAMA. 1998; 279: 1200-05.

Lei HS, Rahman ABFAB, Haq AHSM. Adverse drug reaction reports in Malaysia: Comparison of causality assessments. Malay J Pharm Sci. 2007; 5: 7-17.

McDonnell PJ, Jacobs MR. Hospital admissions resulting from preventable adverse drug reactions. Ann Phrmacother. 2002; 36: 1331-36.

Moore N, Lecointre D, Noblet C, Mabille M. Frequency and cost of adverse drug reactions in a department of general medicine. Br J Clin Pharmacol. 1998; 45: 301-08.

Nahar BL, Hossain AKM, Islam MM, Saha DR. A comparative study on the adverse effects of two anti-tuberculosis drugs regimen in initial two month treatment period. Bangladesh J Pharmacol. 2006; 1: 51-57.

National Medicines Information Centre. Adverse drug reactions. Vol 8, No-3, 2002. Accessed on 27.06.2007 at http://www.ukmi.nhs.uk/Newmaterial/html/docs/ 0807021.pdf.

Nies SA, Spielberg PS. Principles of therapeutics. In: Goodman \& Gilman's The pharmacological basis of therapeutics. 9th ed. New York, Mc Graw-Hill, 1996, pp 43-62.

Palain S, Mishra P, Shankar PR, Dubey AK, Bista D, Almeida R. Safety monitoring of drugs-where do we stand? Kathmandu Univ Med J. 2006; 4: 119-27.

Patel H, Bell D, Molokhia M, Srishanmuganathan J, Patel M, Car J, Majeed A. Trends in hospital admissions for adverse drug reactions in England: Analysis of national hospital episode statistics 1998-2005. BMC Clin Pharmacol. 2007; 7: 9.

Pirmohamed M, Park BK. Adverse drug reactions: Back to the future. J Clin Pharmacol. 2003; 55: 486-92.

Pirmohamed M, James S, Meakin S, Green C, Scott AK, Walley $\mathrm{TJ}$, et al. Adverse drug reactions as cause of admission tohospital: Prospective analysis of 18820 patients. BMJ. 2004; 329: 15-19.

Pouyanne P, Haramburu F, Imbs JL, Bégaud B. Admission to hospital caused by adverse drug reactions: Cross-sectional incidence study. BMJ. 2000; 320: 1036.

Ramesh M, Pandit J, Parthasarathi G. Adverse drug reactions in a South Indian hospital: Their severity and cost involved. Pharmacoepidemiol Drug Safety. 2003; 12: 687-92.

Rao PGM, Archana B, Jose J. Implementation and results of an adverse drug reaction reporting program in an Indian teaching hospital. Indian J Pharmachol. 2006; 38: 4.

Reidl AM, Casillas MA. Adverse drug reactions: Types \& treatment options. American Family Physician. 2003; 1: 68.

Singer DRJ, Khong TK. Adverse drug reactions: Current issues and strategies for prevention and management. Exp Opinon Pharmacother. 2002; 3: 1289-1300.

Suh DC, Woodall BS, Shin SK, Hermes-De-Santis ER. Clinical and economic impact of adverse drug reactions in hospitalized patients. Ann Phrmacother. 2000; 34: 1373-79.

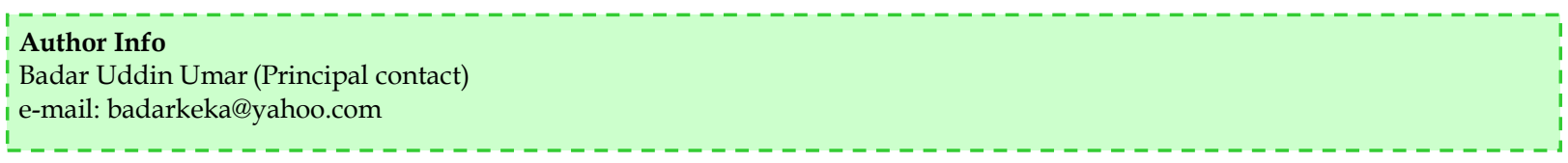

